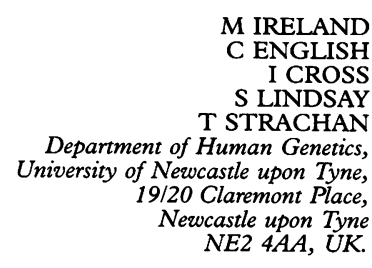

1 Holder SE, Grimsley LM, Palmer RW, Butler LJ, Baraitser M. Partial trisomy $3 \mathrm{q}$ causing mild Cornelia de Lange phenotype. $\mathcal{f}$ Med Genet 1994;31:150-2.

2 Ireland $M$, English C, Cross I, Houlsby WT, Burn J. A de novo translocation $\mathrm{t}(3 ; 17)$ (q26.3 q23.1) in a child with Cornelia de Lange syndrome. $₹$ Med Genet 1991;28:639-40.

3 Smith DI, Glover R, Gemmill R, Drabkin P, O'Connell P, Naylor SL. Report of the fifth international workshop on human some 3 mapping 1994. Cytogenet Cell Genet 1995;68: 126-46.

\section{Response to GIG's response to the UK Clinical Genetics Society report "The genetic testing of children"}

The Genetic Interest Group (GIG) based their response to the Clinical Genetics Society (CGS) report on their perspective "informed by the experience of families directly affected by genetic disorders". GIG's main focus is to argue for the right of parents to have their children tested, except in the case of adult onset conditions. They criticise the CGS for being too negative about testing for childhood onset conditions and for carrier status and insufficiently negative about testing for adult onset conditions.

The arguments given for testing include: "possible freedom from anxiety; facilitating open relationships; and the parents' need to secure the best environment they can for themselves, the child who will develop the disorder, and other children in the family." "Although the vast majority would prefer there not to be a genetic disorder in their family, knowledge comes to be accepted as a fact of life in the same way that other issues are recognised to be individual and integral to any family. It is also our experience that children can cope with information about themselves from an early age and that it is much more often the adult who has a problem in giving information." "Early knowledge of carrier status could help the child adapt to the consequences of being a carrier over a period of time, rather than having the in- formation presented at puberty, when s/he is going through a time of emotional adjustment and may not best handle the information. ... Facts of life are best absorbed slowly and when the moment is right rather than during a crisis over pregnancy."

The arguments given for testing could also apply to adult onset conditions. Differentiating so markedly between child and adult onset raises questions of "what is a child and what is an adult?" and "how should conditions with variable age of onset be deal with?" It is not clear why arguments are used for children to have knowledge of carrier status which only becomes relevant in adulthood (as defined by age at which reproduction is possible) but not to knowledge of adult onset conditions.

GIG cites one argument against testing for adult onset conditions: that testing takes away the child's right as an adult to make an informed decision. This completely ignores the other side of the coin. Not testing takes away the right of the adult to have been brought up with the knowledge that they will or will not develop a genetic condition in adulthood.

GIG criticises the CGS for being patronising and overly preoccupied with the harm that knowledge of genetic disorders can cause within families. They consider that CGS gives insufficient credit to families: "parents are responsible for the welfare of their children and at the end of the day most of them are better equipped to decide what is in the best interest of a particular child, and the family as a whole, than are outsiders. Denying them the right to cope in the way that they see as best may have the opposite effect to that intended."

It is unclear why parents should be seen as having this responsibility for childhood onset, but not adult onset, conditions. Parenting is about building the basis for happy and fulfilled adult lives, not just about doing the best within childhood.

We agree with GIG that "it is both possible to draw up standard, basic, guidelines for testing, and also necessary to do so if best practice is to survive the extra burdens that will result from the expansion of the field." However, this raises the question of the basis upon which such guidelines are to be developed. One key element is the contribution of all relevant perspectives, which should include affected families, voluntary organisations such as GIG, and the general public as well as professionals. But all of these perspectives should be informed by data beyond personal experience.

One of the best ways to resolve these questions is to collect evidence through systematic studies. ${ }^{1}$ While we have, as yet, no ex- perimental or large scale studies to draw upon, we have access to children undergoing predictive genetic testing for late onset conditions as part of routine genetics services. In order to document the perspectives and experiences of these families, we are completing the follow up of a single case study ${ }^{2}$ and initiating a multiple single case study. Just as debates about clinical and social policy should shape the research that is carried out, so research findings should be available to inform these debates.

SUSAN MICHIE THERESA M MARTEAU Psychology $\mathcal{E}$ Genetics Research Group, GMDS, London SE1 9RT, UK

1 Michie S, Marteau TM. Predictive genetic testing in children: the need for psychological research. Br $\mathcal{f}$ Health Psychol (in press).

2 Marteau TM, Michie S. Genetic testing of newborns: the need for evidence. $B M \mathcal{F}$ (in press).

This letter was shown to GIG who reply as follows:

The Genetic Interest Group is pleased that its Letter to the Editor in the June issue on "The genetic testing of children" has aroused interest and possibilities for further debate. We would like to answer a couple of points made by Drs Michie and Marteau.

First, we believe that there is a profound difference in the knowledge that you are a gene carrier with implications for reproduction, and the knowledge that you are at some point in your adult life going to be personally affected by a genetic disorder.

Second, not testing in childhood for adult conditions for which there is no treatment does not of course mean that children should not be aware of their risk status. Experience with Huntington's disease has shown that most people at risk and their partners who have not been informed generally feel angry and deprived of making their own decision in the light of that knowledge. The low take up of the test, however, shows that testing is often not desired.

We welcome the idea of further research and debate from a variety of perspectives. We are currently in conversation with the BMA in the hope of holding a conference on the subject in 1996.

SHIRLEY DALBY Genetic Interest Group, Farringdon Point, 29-35 Farringdon Road, London EC1M $3 f B$, UK 